\title{
Analysis on the Challenges of the HRBP Application in Organizations
}

\author{
Fangyue Shi ${ }^{1, *}$ \\ ${ }^{1}$ The Hong Kong Polytechnic University, Hong Kong \\ *Corresponding author. Email: shilishuang@cas-harbour.org

\begin{abstract}
Over the past years, as a result of developments in the wider environment, many organizations have transformed their HR systems from the traditional model to the Shared Model of HR Services, and the role of the HR practitioner has evolved from dealing with employee relations to being a strategic supporter today. Most of literature describes the value that HRBP can bring to an organization, but few points out the difficulties in the practical application of HRBP. Citing the results of interviews with respondents from organizations in the past literature, this paper collates the three main common challenges to the application of HRBP in organizations from an organizational perspective and gives recommendations to address them accordingly. Through the survey, research and analysis, it is concluded that HR change in some organizations still needs further refinement to address the current shortcomings in practice.
\end{abstract}

Keywords: HRM, The Shared Model, HRBP, Transform challenge

\section{INTRODUCTION}

Richard (2007) describes the evolution of HR's function in terms of its impact and contribution to the business over the last century, as shown in Figure 1, where the role of HR has evolved from the initial employee relationship to its current role as a strategic partner [35]. Maugans (2015) summaries three eras of HR transformation. The first era was developed in the late 19 th century as a result of industrial tensions, which were a result of public concern due to the sometimes violent relationships between employers and employees. Some have described this phase of HR as managers with managerial functions and employee experience [21]. Ulrich \& Dulebohn (2015) refer to this phase of HR transformation as the administrative wave, performing traditional administrative functions, providing $\mathrm{HR}$ services, and working towards regulatory compliance [32]. With the passage of time, human resources entered a second era [32]. Ulrich \& Dulebohn (2015) refer to this phase of HR transformation as a wave of practice, a phase in which HR accumulates knowledge in various areas and offers innovative HR practices. A necessary condition for this wave is to upskill HR employees to become HR professionals rather than lower-level administrators [21]. As the HR profession evolved, the HR role expanded to include strategic business partners (HRBP) in the 1980s, an era where HR professionals were expected to participate in the development and implementation of business strategies [21]. 


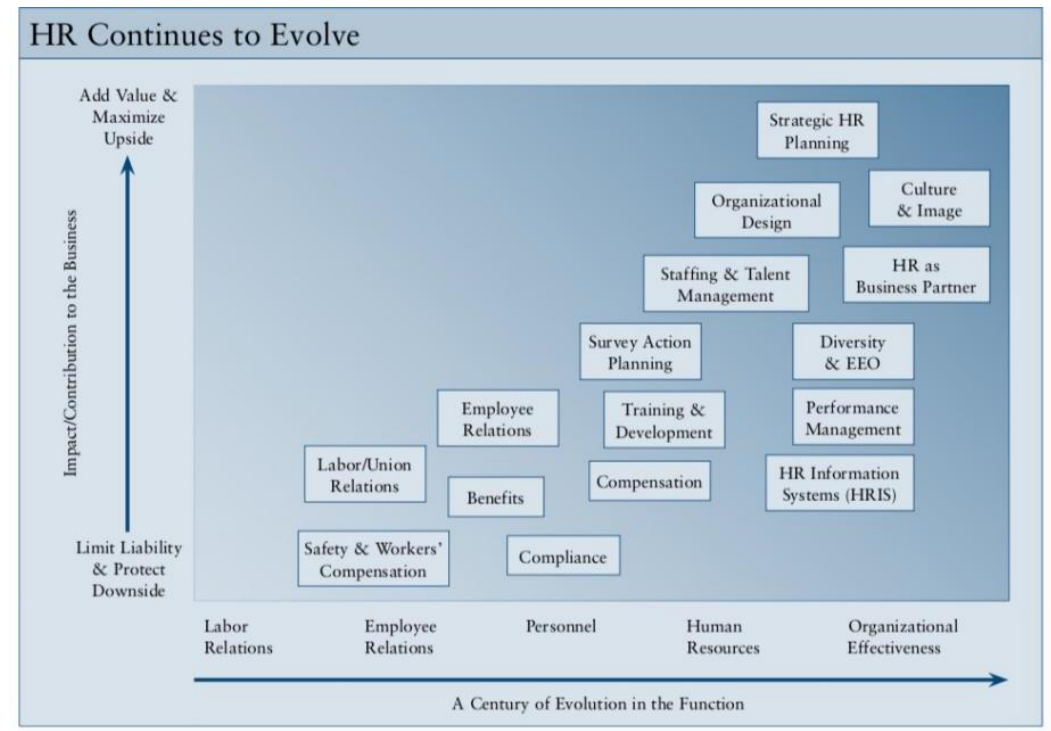

Figure 1. HR Continues to Evolve[35]

In investigating the future of the HRM function, numerous scholars have suggested that the HR function should be upgraded in the face of globalization and greater competition [3]. There are indications that the boundaries between management occupations are breaking down as structures and technologies change and the emergence of new occupational groups encourages the blurring of traditional occupations, i.e. the blurring of functional boundaries within and outside the organization [10]. In the context of the knowledge-based economy, large corporations have begun to seek reforms in their HRM models, allowing HRD to gradually move away from a transactional role and towards a strategic, business-oriented role. Due to its strategic starting point and business-directed characteristics, the Shared Model of HR Services has been increasingly theoretically accepted in the practice of corporate HRM. The model was developed by Ulrich (1997) in his Human Resource Champions book [18], HRCOE, HRSSC and HRBP are jointly composed of HRCOE, HRSSC and HRBP, as shown in Figure 2, HRCOE is responsible for top-down systematic analysis of staff recruitment, performance and remuneration, and providing HRSSC with system standards and strategic layout. The three parties discuss and work closely together to solve the HRM problems of each business department and improve the internal structure of the organization in a timely manner.

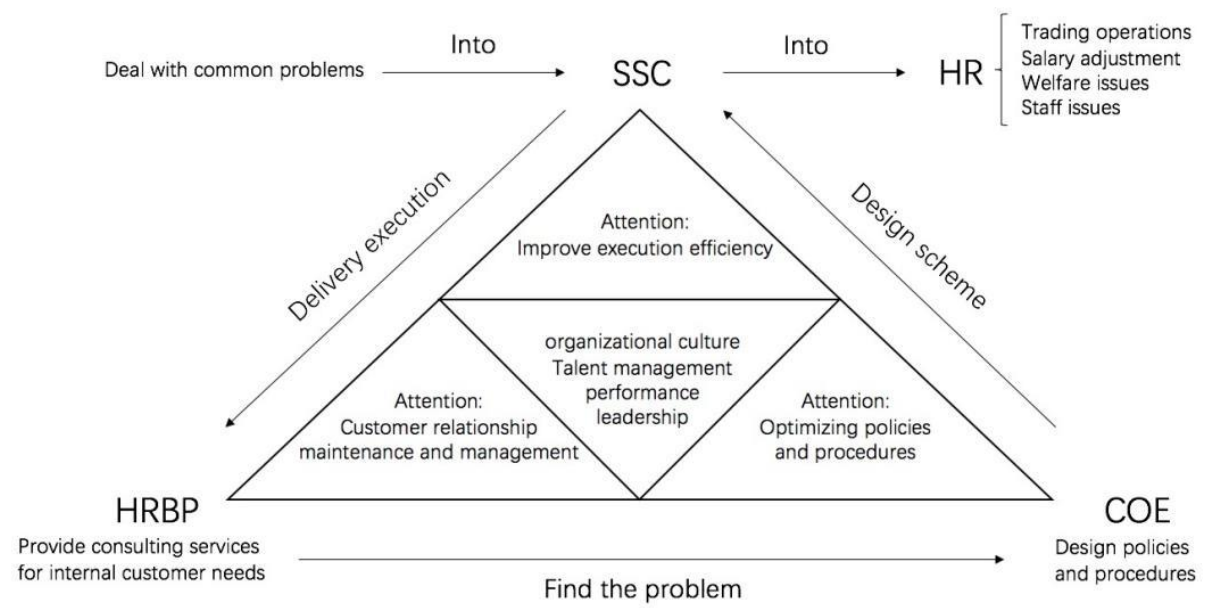

Figure 2. The Shared Model of HR Services[4]

\section{HRBP}

HRBP is one of the components of The Shared Model of HR Services, as shown in Table 1, HRBP plays several roles, the most important of which is to act as a strategic positioner. As shown in Figure 3, the main function of HRBP is to serve business units, to explore their needs and to provide solutions, providing a new way of thinking for companies that are struggling with HR management problems. Working with senior managers to support the achievement of business objectives, line managers will be responsible for many of the tasks traditionally carried out by $\mathrm{HR}$ and will require employees to use HR services in new ways [4]. In addition, HRBP provides the framework 
for the development of HR departments into full strategic players, creating lasting value for stakeholders and representing a shift from execution to delivery [20]. HRBP aims to streamline HR services and support senior HR practitioners in strategic HR activities [2]. Ulrich \& Brockbank (2005) note that sometimes the role of strategic partner among contemporary HR professionals is regarded as a synonym for business partner [13]. Stritesky (2014) found that the role of $\mathrm{HR}$ in organizations has shifted from the executive to the strategic level. This view brought HR professionals more closely aligned with the strategic elements of the company and was given a position as a key contributor to the business [15]. As shown in Table 1, strategic HR requires the HR department to be competent in business issues related to strategy formulation and organizational design. Therefore, HRBP should have the ability to determine which positions have the greatest impact on the strategic success of the company [21].

Table 1. HRBP domains and tasks [13]

\begin{tabular}{|c|c|}
\hline Domain & Description of HRBP' s tasks \\
\hline Strategic Positioner & $\begin{array}{l}\text { The extent to which the HR professional can evaluate both the external and internal business contexts and } \\
\text { translate those evaluations into practical insights that help position the organization to be successful. }\end{array}$ \\
\hline Credible Activist & $\begin{array}{l}\text { The extent to which HR professionals achieve the trust and respect they need within the organization to be } \\
\text { viewed as valued and valuable partners. }\end{array}$ \\
\hline Culture and Change Champion & $\begin{array}{l}\text { By managing both change and culture HR professionals help make things consistently happen within the } \\
\text { organization. }\end{array}$ \\
\hline Human Capital Curator & $\begin{array}{l}\text { Offering integrated and innovative HR solutions for managing people within their organization ensure human } \\
\text { capital development within organization. }\end{array}$ \\
\hline Total Rewards Steward & $\begin{array}{l}\text { Creating total reward systems which include compensation and benefits (financial rewards) as well as } \\
\text { meaning from work (nonfinancial rewards). }\end{array}$ \\
\hline Technology and Media Integrator & $\begin{array}{l}\text { Leveraging technology and technological tools to support their efforts to create high performing } \\
\text { organizations. They also rely on social media to recruit, retain, develop and engage human capital. }\end{array}$ \\
\hline Analytics Designer and Interpreter & $\begin{array}{l}\text { HR professionals must be able to use analytics to impact decision making. Analytics goes beyond collecting } \\
\text { data and having scorecards to using data to improve business decisions. }\end{array}$ \\
\hline Compliance Manager & $\begin{array}{l}\text { HR professional must be able to manage the processes related to compliance by following regulatory } \\
\text { guidelines. The compliance function varies by geography. }\end{array}$ \\
\hline Paradox Navigator & $\begin{array}{l}\text { HR professionals are increasingly asked to maximize ideas and outcomes that may be inherently in } \\
\text { opposition with each other. These professionals must constantly manage the paradoxes or tensions that exist } \\
\text { in work settings. }\end{array}$ \\
\hline
\end{tabular}

Table 2. Five elements and fourteen criteria by Ulrich and Brockbank of the HR value proposition in becoming a strategic business partner [25]

\begin{tabular}{|c|c|c|}
\hline $\begin{array}{l}\text { Premise of the HR } \\
\text { value proposition }\end{array}$ & Elements of the HR value proposition & Criteria for an effective HR function \\
\hline \multirow[t]{11}{*}{$\begin{array}{l}\text { HR succeeds when it } \\
\text { creates value }\end{array}$} & Knowing external business realities & $\begin{array}{l}\text { 1. Recognises external business realities and adapts practices } \\
\text { and allocates resources accordingly. }\end{array}$ \\
\hline & \multirow[t]{3}{*}{ Serving external and internal stakeholders } & $\begin{array}{l}\text { 2. Creates market value for investors by increasing } \\
\text { intangibles. }\end{array}$ \\
\hline & & $\begin{array}{l}\text { 3. Increases customer share by connecting with target } \\
\text { customers. }\end{array}$ \\
\hline & & $\begin{array}{l}\text { 4. Helps line managers deliver strategy by building } \\
\text { organisational capabilities. } \\
5 \text {. Clarifies and establishes an employee value proposition } \\
\text { and ensures employees have the abilities to do their jobs. }\end{array}$ \\
\hline & \multirow[t]{3}{*}{ Crafting HR practices } & $\begin{array}{l}\text { 6. Manages people processes in ways that add value. } \\
\text { 7. Manages performance-management processes and } \\
\text { practices in ways that add value. }\end{array}$ \\
\hline & & $\begin{array}{l}\text { 8. Manages information processes and practices in ways that } \\
\text { add value. }\end{array}$ \\
\hline & & $\begin{array}{l}\text { 9. Manages work-flow processes and practices in ways that } \\
\text { add value. }\end{array}$ \\
\hline & \multirow[t]{2}{*}{ Building HR resources } & $\begin{array}{l}\text { 10. Has a clear strategic planning process for aligning HR } \\
\text { investments with business goals. }\end{array}$ \\
\hline & & 11. Aligns its organisation with the strategy of the business. \\
\hline & \multirow[t]{2}{*}{ Ensuring HR professionalism } & 12. Has staff who play clear and appropriate roles. \\
\hline & & $\begin{array}{l}\text { 13. Builds staff ability to demonstrate HR competencies. } \\
\text { 14. Invests in professionalism through training and } \\
\text { development experiences. }\end{array}$ \\
\hline
\end{tabular}




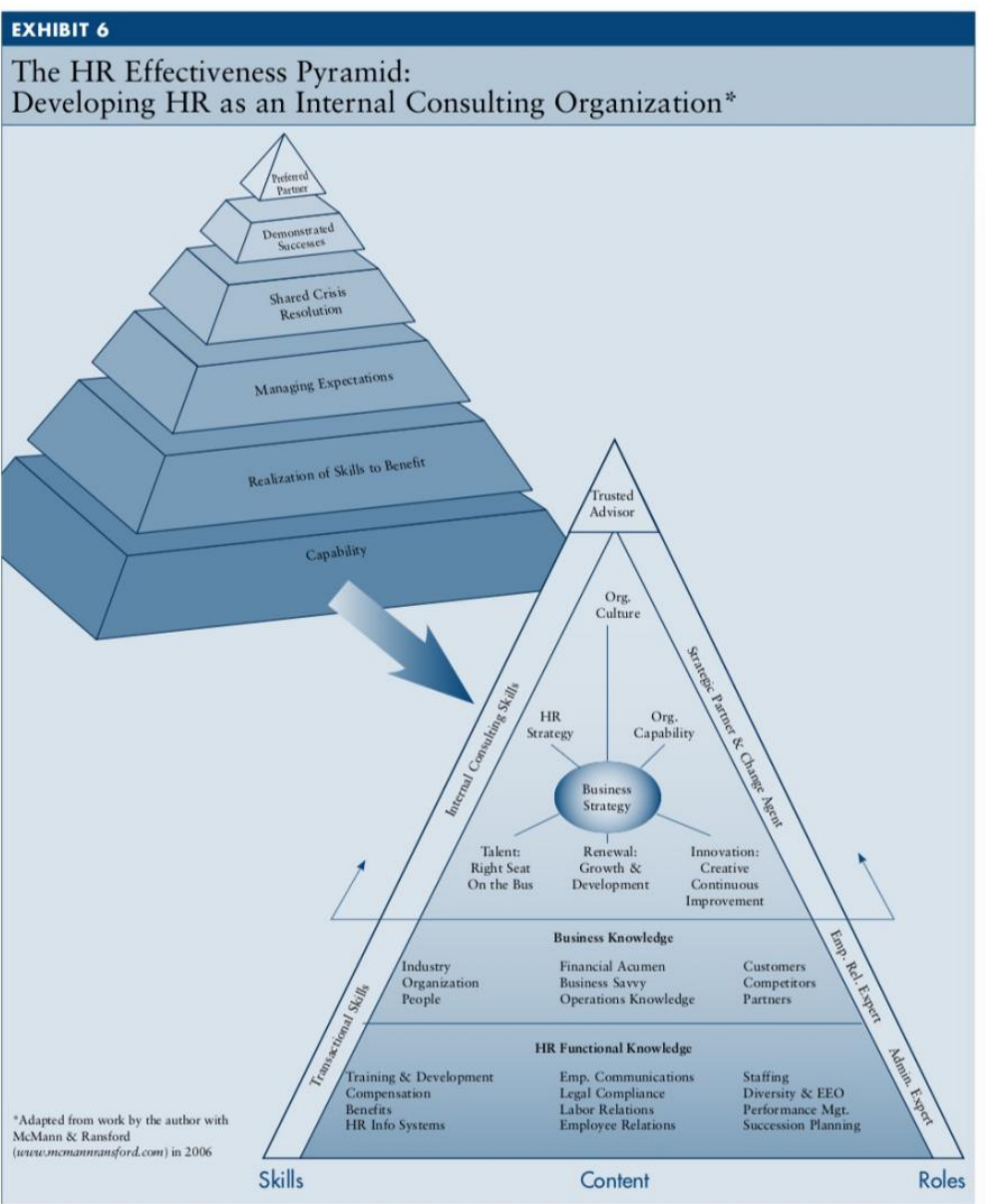

Figure 3. The HR Effectiveness Pyramid [35]

\section{ANALYSIS OF THE PROBLEMS}

Over the past 20 years, both foreign ATC Group, IBM, Big 4 accounting firms and domestic Alibaba, Tencent and Huawei have been continuously exploring and practicing HR transformation. According to statistics, there are about 129 companies implementing The Shared Model of HR Services in China, most of which are concentrated in the Internet industry. In terms of the number of employees, most companies are over 10,000 in size. However, another survey shows that 53\% of companies consider their changes to be unsuccessful, which shows that although many companies are exploring the path of $\mathrm{HR}$ transformation, many end up in failure [43]. Sun (2019) also stated that since the introduction of the HRBP concept in China in 2004, many companies in China have started to apply HRBP, but the results are not significant in the implementation process, and it is still difficult to get rid of the traditional management model, or new problems have emerged [40].

\subsection{Lack of employee supporter role}

The Deloitte Human Capital Trends Report (2013) shows that a typical oversight in accelerating progress in HR is to describe pre-existing HR as BRBP, thereby underestimating other essential components of the HR role [30]. In a survey by Keegan \& Francis (2010), an interviewee specializing in employment law spoke of the inevitable marginalization of "employee champions" in public sector organizations as cost reductions become more apparent. Kessler (1995) and Teo \& Crawford (2005) also point out the potential dangers associated with the erosion of the traditional HRM operational role if too much emphasis is placed on strategy [12]. Peccei (2004) argues that a consequence of the strategic expansion of HR work is an overemphasis on businessoriented performance outcomes, which overshadows the importance of employees' own well-being [11]. Winstanley and Woodall (2000) assert that employee well-being and ethics remain controversial within the realm of human resource development [17]. Ulrich himself argues that the high degree of fit between the HR role as employee champion and management can lead to extreme alienation of employees from $\mathrm{HR}$ and management, which has a clear impact on employee wellbeing [5]. In particular, there has been a tendency to view technology-driven changes in HR service delivery in the same way as technologists and the transfer of HR tasks to line managers, removing the traditional forms of support and advocacy that were previously at the heart of HR work. As a result, there is a clear concern that the title of employee champion has been eroded and face-to-face contact with employees has virtually disappeared [2]. 


\subsection{Low quality of HRBP}

McKinsey reports on a number of European companies claim that, in managing people for high performance, they do not have enough HR professionals with business savvy to support the efforts of business unit leaders [19]. It seems that, especially for HR professionals those who can cross the HR-business boundaries, there is a "talent gap" [3]. Pritchard \& Fear (2015) investigates the HR department of an investment bank and found that the department has adopted The Shared Model of HR Services a year earlier, in which the senior HRBP of the HR department expresses the idea that the organization lacks experienced and expertly qualified R\&D teams and that, in effect only one member of the R\&D team is considered to have some specialists' background, while the others are described as very junior generalists, and the whole team lacks expertise, so that specialist status for the whole team is out of reach [7]. The Sun's study finds that some HRBPs are highly accomplished in the HR field, but they do not bother to learn about the business. When they enter the business sector, they do not understand their clients in the context of the relevant sector, nor do they study projects and markets in depth, which ultimately leads to a disconnect between business sector practices and the company's growth strategy[40]. Wu, Wang, Huang \& Xiao (2020) suggest that another shift is the conversion of business unit staff to HRBPs, who have a good understanding of the business unit but lack HR expertise and may encounter professional bottlenecks [41].

\subsection{Insufficient management attention}

McCracken \& Heaton (2010) conducted 18 research interviews with a range of stakeholders at Energyco, Energyco's senior HRM managers felt that executives and senior managers needed to give HR staff more authority and decision-making power and needed to be more empowered and confident in their abilities, otherwise HR staff would still play a very executive role, which can lead to credibility issues [3]. Sun (2019) agrees and states that the implementation of any policy in a business is closely linked to the attitude of the leader and that if there is no effective communication with the leader or if the leader is not clear about what the change can achieve, then the change will most likely end in failure [40].

\section{SOLUTIONS}

\subsection{Determination on organization size to match the Shared Model}

While The Shared Model of HR Services is great, it is not suitable for every company. Generally speaking, medium and large companies are better suited to apply the HRBP model, especially for fast-growing companies like Huawei, whose original structure was designed to meet the growth needs of the business [40]. Mediumsized companies, which has about 500 employees are unlikely to get profit from the introduction of The Shared Model of HR Services [38]. Sun (2019) says small startups should engage in traditional HR work and don't need to rush to higher-level models[40]. Wu, Wang, Huang \& Xiao (2020) add that HRM can be transformed into an HRBP model when organizations are growing at scale and across regions [41].

\subsection{Employee care requirement at the performance appraisal section}

Ulrich \& Brockbank (2005) notices the attractiveness of the HRBP role among HR professionals, they urge practitioners not to lose sight of employees' role, they advocate and assert that employee relations are intimate, and it is the core of HR work remains caring, listening and responding to employees [16]. Guest (2002) states that most experts in the field agree that relegating employee champions to operational roles undermines the career prospects of HR practitioners who aspire to the role of employee champions, and therefore companies need to build employee well-being-oriented roles in HR work and corresponding appraisal mechanisms that focus more on employee-centred outcomes [6].

\subsection{HRBP quality improvement and credible expert status establishment}

Sun (2019) argues that in order to improve the quality of HRBPs as well as establish credible expert status, HRBPs should become generalists, which means that there are increasing demands on HR practitioners. As HRBPs, they need to understand how business units operate and work with line managers to identify business needs, and they must be innovative and up-to-date, otherwise, in an era of rapid information change, blindly following old information will reduce efficiency and eventually be lost to the market[40]. To avoid this, HRBPs should proactively update their professional knowledge and expand the scope of business knowledge. Companies should place more emphasis on professional knowledge and business knowledge training to provide more professional platforms and opportunities for employees.

\subsection{Emphasis on human resources and power decentralization of management}

Sun (2019) found that changes supported by business leaders are usually more successful, therefore, before the practical application of HRBP, it is essential that HR leaders actively communicate with company leaders to show them the need to change and the benefits that change can bring to the company. In the practical application of HRBP, HRBP must work hard to gain buy- 
in from business leaders, as the main place to implement the HRBP model is in the business unit and if the business unit does not work well together, the implementation will be less effective [40].

\section{CONCLUSION}

HR transformation is more suitable to be applied to large and fast-growing enterprises. The correct application of the HR sharing model can improve organizational efficiency, reduce organizational costs and bring into play the real role of HRBP. In the past decades, many large enterprises at home and abroad have been continuously exploring and practising HR transformation. This paper examines the difficulties in the practical application of HRBP and gives recommendations. Using primary data from previous literature on organizational change respondents, this paper identifies three major challenges that most companies face in applying the HRBP role, namely the lack of employee support roles, the low quality of HRBP and the lack of attention from management and business units. The paper offers four solutions: determining whether the organization is the right size for change, adding employee care-focused assessment criteria to the performance appraisal section to address the lack of employee's wellbeing, improving HRBP quality, establishing the HRBP as a "credible expert", and increasing management's attention and decentralization.

\section{ACKNOWLEDGMENTS}

I would like to express my gratitude to all those who helped me during the writing of this paper. My deepest gratitude goes first and foremost to professor Frank Lichtenberg, my supervisor, for his constant encouragement and guidance. Second, I would like to express my heartfelt gratitude to my tutor Cuihong Wang, who helped me with paper instruction. Last but not the least, my thanks would go to my beloved family for their loving considerations and great confidence in me all through these years.

\section{REFERENCES}

[1] Richard, M., (2007). The Evolution of HR: Developing $\mathrm{HR}$ as an Internal Consulting Organization. People and Strategy. 30(3), 11-23.

[2] Maugans, C., (2015). 21st Century Human Resources: Employee Advocate, Business Partner, or Both?. Cornell HR Review.

[3] Ulrich, D., Dulebohn, J., (2015). Are we there yet? What's next for HR?. Human Resource Management Review. 25, 188-204.

[4] McCracken, M., Heaton, N., (2010). From tucked away to joined at the hip: understanding evolving relationships within the HRBP model in a regional energy company. Human Resource Management Journal [online].

[5] Bowen, D., Galang, C., \& Pillai, R. (2002). The role of human resource management: an exploratory study of cross-country variance. Human Resource Management. 41(1), 103-122.

[6] Wright, C., (2008). Reinventing human resource management: Business partners, internal consultants and the limits to professionalization. Human Relations. 61(8), 1063-1086.

[7] Morris, T. From key advice to execution? Consulting firms and the implementation of strategic decisions. In P. Flood, T. Dromgoole, S. Carroll \& L. Gorman (Eds), Managing strategic implementation: An organizational behaviour perspective. Oxford: Blackwell, 2000, pp. 125-37.

[8] Reed, M. Expert power and control in late modernity: An empirical review and theoretical synthesis. Organization Studies, 1996, 17(4), 573-97.

[9] Li, X., (2020). An Optimization Study on Recruitment System of C Company From the Perspective of HR Three-Pillar. Advances in Social Science, Education and Humanities Research. 517, 839-844.

[10] Matuska, E., Niedzielski, P., (2018). HR Business partner - The range of roles and services. European Journal of Service Management. 28(1), 191-197.

[11] Ulrich, D. (1997). Human resource champions: the next agenda for adding value and delivering results. Boston: Harvard Business School Press.

[12] Wu, D., Li, G., (2019). Research on HRBP Mode of Big Four Accounting Firms. Modern Management. 9(5), 596-605.

[13] Hu, M., (2020). An Exploration for How to Engage Line Managers in HRBP at Sany Heavy Case Organizations. 435, 492-495.

[14] Charman, C., (2014). The people paradox: Changing HR perspectives and imperatives. Commonwealth Governance and Growth. 80-82.

[15] Keegan, A., Francis, H., (2010). Practitioner talk: the changing textscape of HRM and emergence of HR business partnership. The International Journal of Human Resource Management. 21(6), 873-898.

[16] Ulrich, D., \& Brockbank, W., (2005). The HR Value Proposition, Cambridge, MA: Harvard Business School Press.

[17] Stritesky, M., (2014). New HR organizational structures in Czech and Slovak organizations. Social and Behavioral Sciences. 110, 130-139. 
[18] Beer, M., Spector, B., Lawrence, P., Quinn Mills, D. \& Walton, R. Managing human assets. New York: Free Press, 1984.

[19] Schuler, R.S. \& Jackson, S.E. Linking competitive strategies with human resource management practices. Academy of Management Executive, 1987, 1(3), 207-19.

[20] Bruyn, L, Roodt, G., (2009). Applying the criteria of ulrich and brockbank for the assessment of the role of human resources as a strategic business compamy. SA Journal of Human Resource Management [online]. 7(1), 176-186.

[21] Sun, M., (2019). Application Status and Problems of HRBP Mode in China. Advances in Economics, Business and Management Research. 109, 653-656.

[22] Ashokkumar, G., Bhuva, R., (2012). Analysis on the Role of the HR Business Partner and Their Challenges in an Organization. International Journal of Information Technology and Management. 2(1).

[23] Keegan, A., Francis, H., (2010). Practitioner talk: the changing textscape of HRM and emergence of HR business partnership. The International Journal of Human Resource Management [online]. 21(6), 873898.

[24] CIPD Report (2007a), The Changing HR Function: Transforming HR, London: CIPD.

[25] Kessler, G.C. (1995). A model and process for redesigning the HRM role, competencies, and work in a major multinational corporation. Human Resource Management, 34(2), 229-252.

[26] Teo, S.T.T. and Crawford, J. (2005). Indicators of strategic HRM effectiveness: a case study of an Australian public sector agency during commercialization. Public Personnel Management, 34(1), 1-16.

[27] Francis, H., Fear, W., (2006). The changing face of HRM: in search of balance. Human Resource Management Journal. 16(3), 231-249.

[28] Peccei, R. (2004). 'Human resource management and the search for the happy workplace', Inaugural Address, Erasmus Research Institute of Management, Erasmus University, Rotterdam.

[29] Winstanley, D., \& Woodall, J., (2000). The ethical dimension of human resource management. Human Resource Management Journal. 10(2), 5-20.

[30] Francis, H., \& Keegan, A., (2005). Slippery slope. People Management. 26-31.

[31] Guest, D., \& King, Z., (2004). Power, innovation and problem-solving: the personnel managers' three steps to heaven?. Journal of Management Studies. 41(3), 401-423.

[32] Hope-Hailey, V., Farndale, E., \& Truss, C., (2005). The HR department's role in organisational performance. Human Resource Management Journal. 15(3), 49-66.

[33] Aldrich, P., Dietz, G., Clark, T., Hamilton, P., (2014). Establishing HR professionals' influence and credibility: Lessons from the capital markets and investment banking sector. Human Resource Management. 54(1).

[34] Lawson, E., Mueller-Oerlinghausen, J., and Shearn, J.A. (2005). "A dearth of HR talent". McKinsey Quarterly, 2: McKinsey \& Company: www.mckinseyquarterly.com: 13-14.

[35] Caldwell, R., (2010). Are HR Business Partner Competency Models Effective?. Applied HRM Research. 12 (1), 40-58.

[36] Pritchard, K., Fear, W., (2015). Credibility lost: attempting to reclaim an expert identity in an HR professional context. Human Resource Management Journal. 25, 343-363.

[37] Wu, X., Wang, D., Huang, C., Xiao, L., (2020). Research on Three Pillars of Human Resources Management -Taking Huawei as an Example. Advances in Social Science, Education and Humanities Research. 450, 140-143.

[38] Gerpott, F., (2015). The right strategy? Examining the business partner model's functionality for resolving Human Resource Management tensions and discussing alternative directions. German Journal of Research in Human Resource Management. 29(3-4), 214-234.

[40] Ulrich, D. and Brockbank, W. (2005b). The HR Value Proposition, Boston, MA: Harvard Business School Press.

[41] Guest, D., (2002). Human resource management, corporate performance and employee wellbeing: building the worker into HRM. Journal of Industrial Relations. 44(3), 335-358.

[42] Liu, H., Fu, Y., Wang, X., Fang, Y., (2014). Empirical Analysis of the Relationship between HR Professionals' Competency and Enterprise Performance. International Conference on Management Science and Management Innovation. 546-553. 